\title{
Human Immunodeficiency Virus-specific B cells in human breast milk
}

\author{
Edouard Tuaillon*1, Diane Valea ${ }^{2}$, Yassine Al Tabaa1 ${ }^{1}$, Pierre Becquart ${ }^{1}$, \\ Nicolas Meda ${ }^{2}$, Karine Bollore ${ }^{1}$, Jean-Pierre Vendrell ${ }^{1}$ and Philippe Van de \\ Perre $^{1}$
}

Address: ${ }^{1}$ Université Montpellier 1 and CHU Montpellier, Montpellier, France and ${ }^{2}$ Centre Muraz, Bobo-Dioulasso, Burkina Faso

* Corresponding author

\author{
from Fifth Dominique Dormont International Conference. Mother-to-child transmitted viral diseases: from transmission to children care \\ Paris, France. 26-28 March 2009 \\ Published: 22 July 2009 \\ Retrovirology 2009, 6(Suppl I):O8 doi:10.1186/1742-4690-6-SI-O8
}

This abstract is available from: http://www.retrovirology.com/content/6/SI/O8

(C) 2009 Tuaillon et al; licensee BioMed Central Ltd.

\section{Background}

Breast milk is a component of the mucosal immune system, and contains specific antibodies and lymphocytes that may modulate the infectivity of milk, and therefore the risk of HIV-1 transmission via breastfeeding. While secretory antibodies $(\mathrm{Ab})$ have been extensively explored in human breast milk, the existence, features, and function of B lymphocytes remain to be described in this compartment.

\section{Methods}

We analysed breast milk and blood lymphocytes from 12 HIV-1-infected lactating women. All women were treated by anti-retroviral therapy or have been recently exposed to anti-retroviral drugs for prophylaxis of mother-to-child transmission. Milk samples were collected 5 to 42 days post partum. Phenotype of breast milk cells were analyzed by flow cytometry and cells function by ELISpot assays.

\section{Results}

In contrast to their blood counterpart, naive $\mathrm{B}$ cells remained largely underrepresented in breast milk. Breast milk B cells mostly consisted of IgD- memory B cells. They displayed a phenotype of class-switched memory B cell, with few $\mathrm{IgD}^{+}$memory and naive $\mathrm{B}$ cells. As compared with blood, higher percentages of activated B cells $\left(\mathrm{CD} 38^{+}\right)$, large size $\mathrm{B}$ cells, plasmablasts and plasma cells (CD19+, CD20low/-, CD27high, CD138+) were found. This indicates that a significant proportion of breast milk B cells underwent terminal plasma cell differentiation. We also observed a higher frequency of cells secreting spontaneously Ig in breast milk. Among these cells, IgG-secreting cells (SCs) predominated over IgA-SCs as measured by IgELISpot assays. Specific Ab-SCs were investigated following polyclonal activation using the CD40L ligation. The detection of anti-HIV-1-SCs demonstrated the existence of B cells specific to HIV-1 Ag in breast milk from HIV-1infected women. Finally, we observed that breast milk B lymphocytes bore a unique profile of adhesion molecules $\left(\mathrm{CD} 44^{+}, \mathrm{CD} 62 \mathrm{~L}-\alpha 4 / \beta 7^{+/-}, \alpha 4 / \beta 1^{+}\right)$suggesting that these cells may originate from the gut-associated lymphoïd tissue (GALT).

\section{Conclusion}

Breast milk from lactating women infected by HIV-1 contains activated B cells including cells specific to HIV-1 antigens. These cells display a phenotype strikingly different from blood, with a mucosal homing profile related to $\mathrm{B}$ cells located in the GALT. 